\title{
Innovation Management, from Materiality Assessment to Sustainability Reporting, opening the Social Impact Black Box
}

https://doi.org/10.21272/sec.5(1).13-27.2021.

Belen Suarez Lopez, ORCID: https://orcid.org/0000-0002-6323-2621

Reacción Económica Social Innovation Think Tank CEO, Lead Economist Researcher; ISO TC 279 Expert at WG1-WG3. Team Leader at Blockhub.eu. Audit Consultant- CIA P. Spain

Antonio Vargas Alcaide, ORCID: https://orcid.org/0000-0002-9791-2377

Reacción Económica Communication and Reporting Vice-president. Economist Research, PMP at Blockhub.eu, Spain

\begin{abstract}
When the impossible becomes inevitable. The covid-19 has disrupted increasing the speed of changes in the Industry 4.0, highlighting the need to make a paradigm shift from ego-system to eco-system perspective, challenging organizations and citizens to react from their changemakers role. Two crucial needs arise: firstly, the need to innovate to address the tremendous and complex challenges we face and on the other hand, the need to assess and manage our social impacts. Most organizations should redesign their purpose to focus on measuring, monitoring, and reporting not only in financial terms but also taking into account the non-financial performance, especially in terms of sustainability. Some authors names this time, the era of "stakeholders capitalism". This paper summarizes the arguments and counterarguments within the scientific, standardization, and business discussion on understanding how organizations could measure their financial, environmental, and social impacts; how to increase the quality of the sustainability reporting, and deliver the most benefit for their stakeholders. The article analyzes the pathway of Innovating, Evaluating and Reporting the Impact, using the materiality assessment as a driver to create value thanks to disruptive technologies as Artificial Intelligence, Blockchain and the Internet of things. The result of the study can be practically valuable for many stakeholders: the Organizations Management and Boards, Chief Innovation Officers and Teams responsible for Sustainability reporting, Auditors assuring the reliability of sustainable reporting, the Scientifics researching on the topic of Innovation, Impact Assessment, and Sustainability; Public Administrations for addressing the economic, social and environmental challenges, and building trust by ensuring transparency and accountability; Investors and other stakeholders interested on understanding long-term value creation and the social and environmental risk assessment to incentivize sustainable growth.
\end{abstract}

Keywords: innovation, materiality, social impact management, sustainability reporting, standardization, information, data management, ecology.

JEL Classification: O03, G32, Q56, Q51, M41, M42.

Cite as: Suarez B., Vargas, A. (2021). Innovation Management, from Materiality Assessment to Sustainability Reporting, opening the Social Impact Black Box. SocioEconomic Challenges, 5(1), 13-27. https://doi.org/10.21272/sec.5(1).13-27.2021.

Received: 15.02 .2021

Accepted: 22.03 .2021

Published: 30.03 .2021

Copyright: (C) 2021 by the authors. Licensee Sumy State University, Ukraine. This article is an open access article distributed under the terms and conditions of the Creative Commons Attribution (CC BY) license (https:// creativecommons.org/licenses/by/4.0/). 


\section{Introduction}

2020 was an inflexion point since the pandemic has accelerated previous trends. Given the urgency and the severity of the crisis, we face the most large-scale, urgent, and complex economic, social, and environmental challenges in our recent history. People are starting to realize that value, health, and wealth are intertwined more than we never thought. The need to make a paradigm shift from the ego-system to an ecosystem perspective is vital.

In the last decades, within a centric ego-system perspective, the organizations were structured to satisfy shareholder needs, while privatizing decision-making, and the financial capital was perceived above other contributions, and the costs and transactions suffered a lack of transparency. However, the pandemic forces us to think from the perspective of the ecosystem, starting to take care not only of ourselves but in the interest of the entire ecosystem, reconsidering values like transparency.

Numerous studies point to growing demand from civil society, business and political leaders, the academic world, and global institutions, to align their economic options with their values. At the same time, a wave of innovation and entrepreneurship is unleashing what it can be named scalable solutions to pressing global challenges. Its growth accelerates the transition to more inclusive, sustainable, and resilient economies (OEDC RT, 2018). It's remarkable the need to work with public and private collaborations while involving civil society, and the need to transfer the scientific knowledge towards alliances. From the quadruple helix perspective, this new wave will develop transformative and inclusive changes, working from double materiality to involucrate stakeholders, making decisions with better intuition, and identifying gaps where more social value could be creating.

Organizations need to understand the societal expectations of their stakeholders. They should tend to carry out a systematic dialogue with their key stakeholders like investors, customers, suppliers, peers, regulators, and others who will be impacted by their innovations. This dialogue helps to understand their difficulties and how the organization impacts the planet.

From the materiality assessment, the organization would obtain relevant information to define its strategy and allocate resources to the most important issues adapted to its context. Furthermore, to build strong relationships with its stakeholders, the organization would have a comprehensive assessment of where it matters most make better decisions, improve its communication, and strengthen trust with society.

It is necessary to provide a better understanding of several issues: firstly, how companies measure and report their impacts; secondly, how consumers discern between what companies have a positive impact on the environment versus those who simply claim to be impactful, a trend which is named "impact washing"; and thirdly, how the investors could compare companies when their values are assessed by the lens of risk-return-impact.

Scientific evidence suggests that public sentiment influences investor views about the value of sustainability activities and that big ESG (Environmental, Social, and Governance) data can be useful in identifying "value" ESG stocks. (Serafeim, 2020). Monetize the impacts that organizations, innovations, products, and activities have on people and the planet, introducing intangible and non-financial factors in the analysis, would allow to increase or decrease to corporate results value, ensuring that the data provided are accurate representations (Kishan, 2020).

This paper summarizes the arguments and counterarguments within a standardization approach for transforming the way innovation and impact data is collected, verified, and analyzed, for giving investors, businesses and consumers access to reliable and actionable impact information that enables them to make data-driven decisions.

\section{Literature review}

This paper summarizes the arguments and counterarguments within the scientific discussion on the issue. The scientific literature has been complemented with international standards provide by International Standardization Organisms both at Innovation and at Impact assessment point of view. The core of the analysis is composed of articles and researches analyzing a wide range of topics as for example Social Innovation, The Measurement of Scientific, Technological, and Innovation Activities, professional auditor studies, or potential applications of Artificial Intelligence and Blockchain to face Socio-economic challenges. The scientific literature has been 
complemented also, with the dissemination provided by the International Institutions Reports to provide a big picture and integrate the main stakeholder's point of view.

Due to the complexity of the assessment, and with the purpose to obtain the big picture of the process, the extensive taxonomy of literature review could be summarized and classified into three main blocks:

1. The first block, definition, and main features of Innovation and Social Impact Assessment, providing the point of academics, for example, Porter, et al. (2019), Serafeim G (2020) or Krlev, G., Bund, E., et Mildenberger, G. (2014).

2. The second block, analysis of international Standards on Innovation and Impact Assessment, which are redacted in collaboration with the Academia, such as ISO 56002

3. The third block, a systematic assessment about the perspective of International Organisms and main Audit Agencies, for example, Oslo Manual (2018) or KPMG, (2020).

\section{Methodology research and methods}

The scientific and standardization literature review provides the core of knowledge and background from which to define the frontier between concepts and assess the state of the art. This scientific research has been based on a qualitative analysis, which should be complemented by subsequent empirical analysis.

The research starts from the hypothesis: for evaluating, managing and reporting on innovation and its social impact, is needed to provide the adequate methodology adapted to the specific context of each entity.

Innovation, projects, activities, or investments should be supported not only by an adequate materiality assessment but also for working from standards which facilitate the comparison and provide reliability and transparency of the sustainable reporting to all stakeholders.

The research started with the individualized analysis of three main concepts: Materiality, Social Impact, and Innovation. In a second stage, the researchers analyzed a possible conceptual framework to explain the data flow needed for added value assessment of innovations and their social impacts, drafting an evaluation of the interaction between Social Innovation, social Investment and Sustainable Reporting.

The systematization of the literary sources and approaches for solving the problem addressing by the research indicates that the combined use of new technologies like Blockchain and Artificial Intelligence could overcome the main difficulties for collecting data in real-time and in a synchronized manner, with the quality needed and oriented to the purpose.

\section{Result}

Let will start with the definition of some concepts, which have diverse meanings according to the users. Without a clear definition of the concepts and clarification of their scope, the analysis of the creation of value and impact assessment represents even a more complex exercise.

\subsection{Concepts Definition}

This research summarizes the scientific literature and is provided by the most recognized international organizations in each of the fields of Materiality, Social Impact, Innovation.

\section{A. Materiality}

According to the IIRC and the International Federation of Accountants, "a matter is material if it could substantively affect the organization's ability to create value in the short, medium or long term" (International Integrated Reporting Council, 2015, p. 8).

In conventional and symbolic use, materiality implies substance or importance in evaluating criteria and reaching judgments. In accounting, the term "material" appeared, as an adjective, at the turn of the 20th century in accounting and auditing texts issued by the American Institute of Certified Public Accountants (Edgley, 2014). 
Since then, several authors (Brennan et Gray, 2005) have recognized the common characteristics of materiality that help companies to disclose a true and fair view of themselves. Information is considered material if its omission or misstatement could affect the economic decisions of users (Edgley, 2014).

The Sustainability Accounting Standard Board (2013) defines materiality as a long-term focus on the issues that make a difference to both an organization's performance and management priorities and on the information needed to make sound judgments.

Materiality assessment is crucial in the implementation of Corporate Social Responsibility (CSR) strategy and sustainable reporting, which requires the organization to improve a process of communicating the social, ethical, and environmental effects of their actions to particular interest groups within society (Gray et al., 1987).

Concerning non-financial information reporting, which is often totally voluntary in fact, it is essential to have a precise and correct principle that guides organizations in identifying which topics to measure, to report and which level of detail to use (Balluchi et al., 2019).

In this respect, the main dilemma for companies is how to recognize relevant issues to be disclosed in sustainability reporting and to prioritize those material issues following stakeholder demands (Hsu et al., 2013). The process of accountability requires the company to understand the need for information on the part of management, investors, and all the stakeholders who can affect the company's long-term performance. Companies must consider and apply the concept of materiality. (Balluchi et al., 2019).

A considerable part of the literature offers different approaches to the measurement of the CSR commitments disclosed by the company. Among these studies, many focus on the importance of engagement to ensure good and effective dissemination. Font et al., 2016, suggest four different frameworks to clarify the reasons for the Commitment to CSR, which may explain the shift towards more material CSR practices and, therefore, communication. (Balluchi et al., 2019):

1. Theory of reputation and risk management, based on the avoidance of factors that can hurt corporate brands (Bebbington et al., 2008).

2. Resource-based vision of the company, which suggests that companies act responsibly to maximize their competitive advantage (Russo et Fouts, 1997).

3. Stakeholder theory, which suggests that companies act in Responding to stakeholder wishes, either preventively or proactively path (Wood, 1991); sustainability reports become channels to meet the information requirements of different stakeholder groups.

4. Creation of shared value, which explains the commitment of the purpose of creating value and product distinction. This should combine with an attitude towards stakeholders to provide success and create value (Porter et Kramer, 2006; Wheeler et al., 2003).

\section{B. Social Impact}

To define Impact we will considered both the international standards organization point of view and the review of the scientific literature.

From the perspective of Standards Organizations, there are several approaches, among them: The Global Reporting Initiative (GRI), which is an independent institution that created the first global standard of guidelines for the preparation of sustainability reports for companies that wish to evaluate their economic, environmental, and social performance. The GRI Standards define the impact as the effect that has an organization on the economy, the environment and/or society, cuold indicate its contribution (positive or negative) to sustainability development (GRI, G4, 2013). Making a difference with the impact as an effect on an organization, for example, the change in its reputation. 
The concept of social impact, therefore, differs from the 'impacts of the organization' understood as the impacts experienced by the organization itself, considering as material only those impacts that could have significant consequences for the organization itself.

To determine their social impact, organizations must identify material issues considering either or both of the following two dimensions: (1) the importance of the organization's economic, environmental and social impacts, that is, its importance to the economy, the environment, or society. As well as (2) its substantial influence on stakeholder assessments and decisions.

Organizations need to communicate about the impacts they have on the economy, the environment, and society. They must provide stakeholders with information about the organization's contributions, positive or negative, towards the goal of sustainable development.

Therefore, organizations must determine the material problems, revealing the full picture of their significant external impacts, not just those impacts that have immediate consequences from a business perspective, such as financial costs or a damaged reputation.

In a similar approach, according to The Impact Management Project (IMP), a community of more than 2000 professionals working to provide and build a global consensus on how to measure, manage and report impacts on sustainability, Impact is defined as a change in an outcome caused by an organization, it can be positive or negative, intentional or not. This definition could apply from the perspective of companies and investors who want to manage environmental, social, and governance (ESG) risks, as well as those who also want to contribute positively to global objectives.

The IMP considers that the impact can be measured from five dimensions:

1) What are the results of the impact?

2) Who experiences the results of the impact?

3) To what extent does the impact result occur?

4) What is the organization's contribution to the impact result?

5) What is the risk if the result of the impact does not occur as expected?

The goal of this model is to analyze the impact from a more granular level, considering who benefits from the impact and the risks associated with failure to achieve success.

While the scientific community, as well as the business world, highlights the need to establish a common measurement standard and indicators from which to compare the impact generated by organizations at an international level, yet another part of the scientific community calls attention to the need for carrying out evaluations and audits based on the criterion of materiality, adapted to the industry itself and the type of innovation, due to the broad set and complexity of criteria.

The lack of consistent, universal metrics to measure companies' environmental, social and governance performance is often cited as one of the primary obstacles for investors in integrating ESG in their investment process, and to companies' ability to compare their performance to peers. While many organizations and investors express interest in further adopting sustainability strategies, these efforts can be impeded without reliable data.

The World Economic Forum also announced that it has started to collaborate with the Impact Management Project to bring together the efforts of the five leading independent global framework and standard-setters to work towards a comprehensive corporate reporting system.

\section{Innovation}

In general, the concept of innovation a rather complex and multifaceted, his study is the subject of many scientific studies, however, without a generally accepted definition of innovation in science. There are different approaches to the consideration of the term (Kogabayev et al., 2017) 
According to the Oslo Manual, the term innovation can signify both activity and the outcome of the activity. The general definition of innovation is as follows: "An innovation is a new or improved product or process (or a combination thereof) that differs significantly from the unit's previous products or processes and that has been made available to potential users (product) or brought into use by the unit (process)."

This definition uses the generic term 'unit' to describe the actor responsible for the innovations, referencing any institutional unit in any sector. (Oslo Manual, 2018)

Although the concept of innovation is inherently subjective, its application becomes quite objective and comparable through the application of common benchmarks for novelty and usefulness, as well as through guidance provided by the international standardization bodies such as the International Organization for Standardization, concretely the ISO 56000 family of standards which define innovation such "new or changed entity realizing or redistributing value"

The ISO 56002 Standard guides on implementing and using an innovation management system in the organization. It establishes some principles such as "An organization's ability to innovate is recognized as a key factor for sustained growth, economic viability increased well-being, and the development of society", establishing that, "an organization can innovate more effectively and efficiently if all necessary activities and other interrelated or interacting elements are managed as a system".

This standard determines that "an innovation management system guides the organization to determine its innovation vision, strategy, policy, and objectives, and to establish the support and processes needed to achieve the intended outcomes".

The innovation system is a set of interrelated and interacting elements, aiming for the realization of value. ISO 56002 provides a "Plan-Do-Check-Act (PDCA) cycle that enables continuous improvement of the innovation management system to ensure that the innovation initiatives and processes are adequately supported, resourced, and managed and that opportunities and risks are identified and addressed by the organization". This approach can be applied to the innovation management system as a whole or its parts (ISO 56002, 2019).

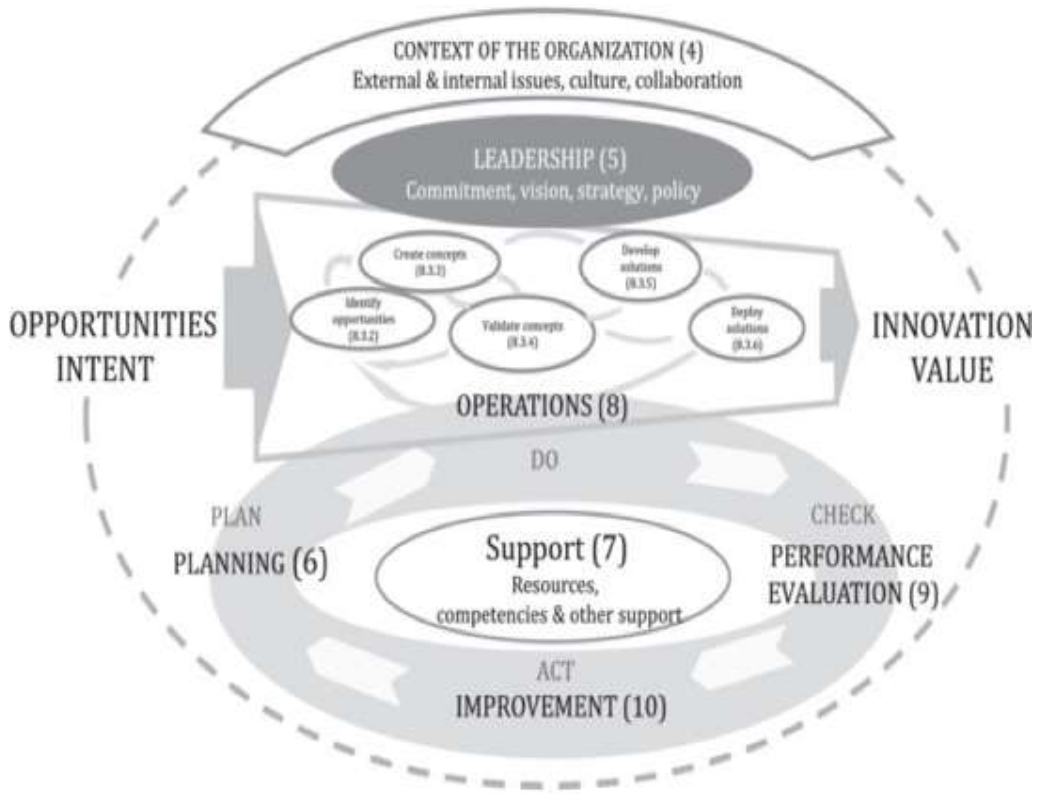

Figure 1. Representation of the framework of the innovation management system with references to the clauses of the document

Source: ISO 56002.

The concept of materiality applied to the scope of Innovation is fundamental in the field of both financial and non-financial information, especially in the last in which we find a lack of (or minimal) regulatory indications 
regarding the contents to be reported. Currently, ISO is developing a guidance standard ISO 56007 on Idea Management and the ISO 56008 standard guidance for Innovation Operation Measurements.

Once the concepts have been defined, this research begins to analyze the interrelation between them and their importance to analyze the contribution of value that any innovation should pursue.

\subsection{Innovation value assessment. Conceptual framework}

This research reinforces the literature that analyzes the Theory of Change through the combination of the innovation cycle and its phases established by the standards, to measure Innovation activity (ISO56002, 2019), as well as by the Logical Framework for analysis of its impact, according to the two components of the definition of Innovation established in the previous section (Oslo Manual, 2018). As a consequence we can establish the innovation activities life cycle through the pathway: beginning with the generation of ideas detected from the materiality assessment and the necessary exercise to understand the context, the organization develops an interactive and no-linear process with the main stages: 1. Identify Opportunities, 2. Create Concepts, 3. Validate Concepts, 4. Develop Solutions, and 5. Deploy solutions. The value created as output and outcomes may start to be realized in the final stage of the innovation implementation process because it is from this moment one we could consider that the Innovation would produce effects and the first evidence of initial effects could begin to be found.

The result could be classified according to the Logic Model as Output, Outcomes, and Impacts. To define this concept we consider the approach provide by IMP:

- $\quad$ Outputs: the immediate results of the innovation activity and necessary to achieve the outcomes.

- $\quad$ Outcomes: the intended and unintended changes that the stakeholders are experiences or might experience with the implementation of the Innovation. According to the Theory of Change is needed to consider outcomes in the short, mid, and long terms.

- $\quad$ Impact: the systemic change that the organization expects to see in the long term. Longer-term socioeconomic consequences, which may affect either direct stakeholders of the innovation activities or indirect other third parties affected due to the interaction with exogenous factors.

This classification is extremely important because the impact needs to be specific and measurable according to the materiality established by the stakeholders. The next figure summarizes the interaction between the defined concepts:

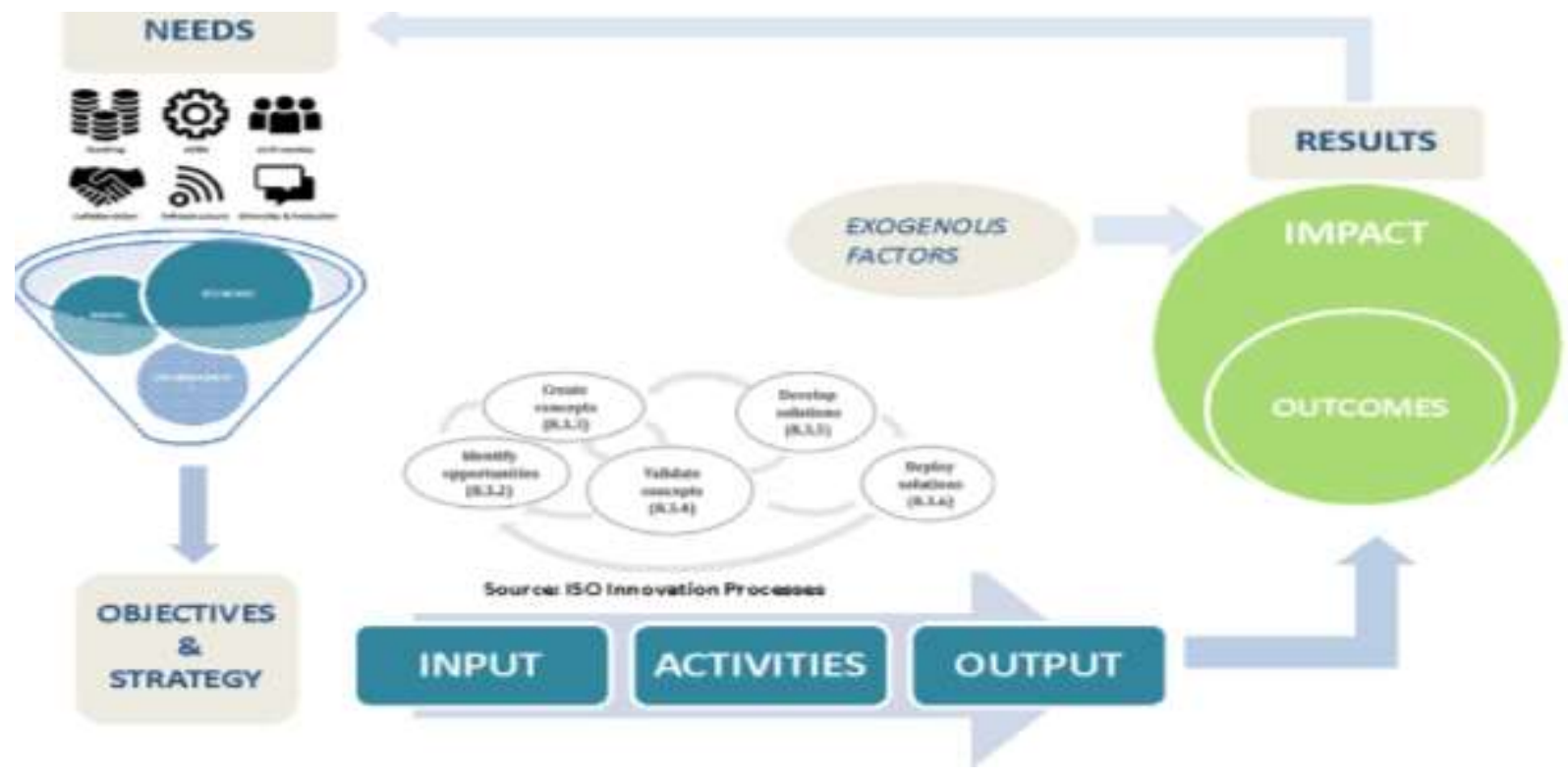

Figure 2. Logic model framework

Source: compiles by authors. 


\subsection{Social innovation and social investment}

Some authors understand social innovation as "A novel solution to a social problem that is more effective, efficient, sustainable or fair than existing solutions, and so that the value created is mainly accumulated for society as a whole instead of individuals" (Phills et al., 2008: 39), as a consequence social innovation is a complex process, which requires collaboration between different actors and scope with social, environmental and economic dimensions.

Systemic change is the main objective of social innovation. Measuring the value of social innovation as an activity in itself is, therefore, a complex exercise, a complementary difficulty to the aforementioned challenge of evaluation and reporting of social impact.

Following the definition of innovation provided by the Oslo Manual and applied to the field of social innovation, this research identifies the activity dimension as social innovation scope and its outcome dimension as the social impact associated.

Social innovation helps to solve unmet social needs through open innovations, social movements, legislation, technologies, new or improved products, processes, or services, etc. In this sense, the scope of social innovation includes new ideas that satisfy social needs, generate social relationships, and forms new collaborations. Social Innovation could include multiple dimensions and researchers face the challenge of creating a unified global approach to measure the value of social innovation (Krlev et al., 2014).

It is highlighted the need in the field of research to evaluate the environmental and social aspects of innovations but also needs to help understand the importance and impact of social innovations in the activity of the organization, paying particular attention to the ability to measure it (Vavra et al., 2011).

To answer the question of how to measure the value of innovation at the level of an organization, there is no preferred methodology among professionals and the scientific community in the matter.

Management literature has developed a slew of three-letter acronyms to refer to considering societal benefits as part of the assessment of business results. There's CSR "corporate social responsibility", TBL the "triple bottom line," referring to social, environmental, and financial performance; and the latest label of choice for private and public organizations, ESG about the "environmental, social and governance" concerns.

A proposed conceptual framework for measuring the value of social innovation includes the triple bottom line approach and covers the economic, social, and environmental dimensions. Elkington presented the idea of sustainability as a "triple bottom line" (TBL) around 1997. The TBL emerged as a new accounting framework that incorporates three dimensions of the organization's activity: social, environmental and financial. (Slaper et Hall, 2011; Hubbard, 2009). According to Hubbard (2009, 80), the TBL "is based on the idea that a company must measure its performance concerning stakeholders, including communities and local governments, not just stakeholders with whom it has direct transactional relationships (such as employees, suppliers and customers)". The TBL is measuring the impact of an organization's activities, including its profitability, shareholder values, and its social, human, and environmental capital (Savitz et Weber, 2006).

The main problem during the development of such approaches is related both to the lack of quality and quantitative databases, which contain several social together to the challenge of identifying sets of indicators appropriate to each entity for measuring the value of social innovation.

The research will use simultaneously the generic terms unit or organization to describe the actor responsible for the innovations, referring to any institutional unit in any sector. (Oslo Manual, 2018). It is difficult to establish the limits of the typology of actors with the capacity to carry out social innovations. In recent decades, many forprofit companies have expanded their purpose to pursue social and environmental goals, while many government and non-profit organizations have adopted market-based approaches to further their goals.

The taxonomy of actors is wide and the border between different categories is diffuse, from a rich diversity of companies and organizations privates or the public, such as cooperatives, mutuals, associations, foundations, social enterprises, and joint institutions, etc., or hybrid organizations with the purpose to address social challenges without profit (Third Sector) or for-profit (Fourth Sector). Increased impact investing, sustainable business, 
corporate social responsibility, public benefit corporations, social enterprise, venture philanthropy, mindful capitalism, and integrated reporting are just a few examples of these trends (OEDC RT, 2018).

Some authors such as M. Porter, which define Shared Value as profit-driven social impact, highlight the opportunities for greater growth, profitability, and competitive advantage that arise from addressing social and environmental issues as an integral part of a company's core strategic positioning.

When investors only pursuit alpha, they ignore their social responsibility, failing to adequately assess the connection between company strategy, social purpose, and economic value. The integration of social factors in the competitive strategy allows to differentiate products, expand markets, improve human resources, or improve the local business environment of a company.

Scientific evidence has shown that when companies focus their sustainability efforts primarily on material social and environmental factors, they significantly outperform the market, with an alpha of 3 to 6 per cent annually. They also outperform peer companies that focus sustainability efforts on non-material factors. (Serafeim, 2020).

The generation of benefits is a necessary but not sufficient condition, a company can generate many benefits, but if it does not generate a positive impact, it will use those benefits to finance its inefficiencies. Linking social impact with corporate strategy creates shared value.

Creating social impact through an innovative and profitable business model modifies the nature of competition.

According to the authors creating shared value is fundamentally different from making incremental improvements on a long checklist of ESG factors that tend to converge over time in any given industry. Shared value companies make a different set of options than their competitors, creating a distinctive social impact on their business models. As a result, they can offer different returns to their shareholders (Porter et al., 2019).

\subsection{Pathway data to the impact assessment and sustainable reporting}

To carry out an adequate impact evaluation, it is essential to provide an objective and impartial dynamic overview of the performance of innovations in a consistent, reliable, and comparable way. Characteristics that are fundamental to guarantee transparency and accountability, allowing decision-makers to establish strategies, define objectives, monitor, and evaluate their deliveries, based on evidence that helps to question established practices and make improvements.

A paradigm shift for transforming the way impact data is collected, verified, and analyzed, giving stakeholders as investors, businesses and consumers access to reliable and actionable impact information that enables them to make data-driven decisions.

As a proposal to obtain the data flow necessary to achieve the purpose of providing relevant and useful sustainable reporting from the perspective of materiality, the research establishes the next systematic process:

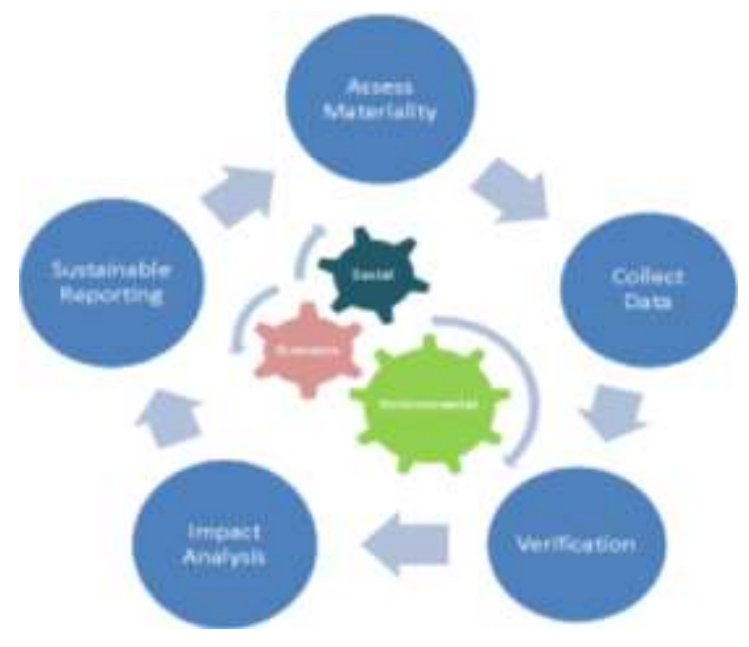

Figure 3. Data flow for sustainable reporting

Source: compiled by authors. 


\section{A. Materiality Assessment}

To understand the societal expectation and showcase how the unit impacts, it is needed to build trust with a systematic stakeholder engagement process, to identify what matters most to the stakeholders and how the unit's innovation could impact their lives.

Understand the relevant issues allows for the selection of objectives, the definition of the strategy, and managing of its financial, environmental, and social impacts delivering better benefits for all stakeholders.

The assessment could follow a multi-stage process that should include:

$>$ Identify the main stakeholders (beneficiaries, investors, workers, customers, suppliers, peers, regulators, etc.). Conducting a holistic stakeholders analysis, targeting both internal and external stakeholders from all relevant categories.

$>$ Collecting quantitative feedback from them through surveys and investigations to rate relevant issues according to the importance of each topic.

$>$ Gaining qualitative insight, through qualitative assessment techniques as interviews, workshops, etc, to learn why the select issues are considered important.

The assessment should provide to the organization a critical input to inform its strategy, helping to allocate resources to the most important issues tailored to the context it operates, supporting the decisión making processes, and improving the communication flow with all stakeholders in a bidirectional manner.

From the materiality assessment, stakeholders need to be consulted regularly regarding their potential and emerging needs, so priority needs have to be identified, met, and reflected in the work programs. Stakeholder satisfaction has to be monitored and followed up on a regular and systematic basis.

\section{B. Data collection}

The 2030 agenda, which represents the greatest coordinated commitment to achieve the social impact of our contemporary era requires the production of an unprecedented amount of quality, timely and disaggregated data to measure progress against its 232 global and other indicators at the national level.

By some estimates, 2.5 trillion bytes of data are created every day (Marr, 2018) and most of the data were created in recent years, such an increase creates opportunities and challenges for data producers, data providers, and data users. Today's data comes from multiple sources and purposes, generated by different producers. In this context, ensuring high-quality and reliable data is becoming a real bottleneck. Ensure credibility, trustworthiness, and quality of data constitutes the basis for tracking progress against any kind of objectives and more concretely into the impact assessment scope.

The complexity of the evaluation to be carried outcomes from the diversity of information sources, internal and internal, as well as the thematic diversity, having to collect data from people (through surveys, community evaluation and individual behavior), environmental data (provided by IoT and device data, geolocation, digital media, real objective data, etc.) as well as the organizational's economic data (from self-reported operational and financial information, proprietary data sets, audits). The organization must collect relevant operational and transactional data from both internal and external incorporating information from its ecosystem. The organization also has to select a repository of impact metrics from which to monitor and show its performance concerning its impact KPIs selected (Heyns, 2021).

Therefore, the analysis must incorporate quality administrative and statistical data. Providing trustworthiness is key for data producers. The concept of "quality" is broad and there are several general definitions of quality. In statistical terms and from a user perspective is defined as fit-for-use or fit-for-purpose.

To safeguard public trust and credibility and assure quality, countries adopt a national code of practice and/or a statistical quality assurance framework (SQAF)1 to implement the ten fundamental principles established by 
United Nations, which have been globally recognized and best practices. (UN, 2015). Based on the template included, producers of official statistics assure the following main quality dimensions:
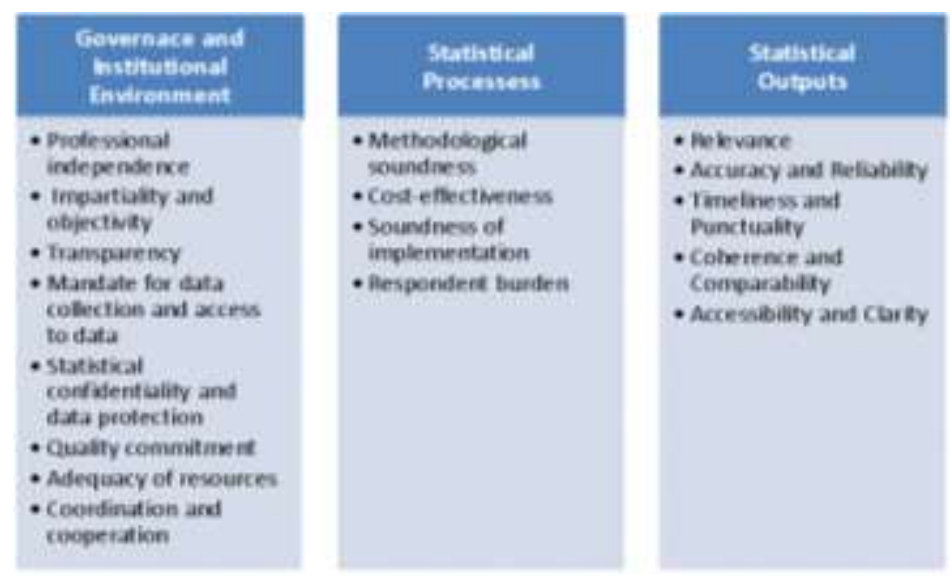

Figure 4. Main quality dimension according to the Statisctical Quality Assuarance Framework (SQAF)1 to implementthe UN-FPOS and best practices

Source: United Nation 2016.

\section{Verification}

As has already been pointed out, the quality is another weakness to overcome in addition to the problem of lack of relevant data for the analysis. The transparency and reliability of the administrative data represent critical problems since is generally stored in centralized and opaque systems, and there is not always enough confidence regarding the possibility that it has been altered or manipulated before reporting.

In most cases, data collection is highly fragmented and siloed across organizations and even departments, with little or no integration of data channels. The consequence is a set of related, but unsynchronized, workflows for performance monitoring and reporting, resulting in resource-intensive data silos and analytics. (Heyns, 2021).

The use of Artificial Intelligence (AI) and Blockchain could improve the quality of the data and the subsequent analysis. As it is necessary to combine internally generated data in large quantities with external data from a variety of information sources, it becomes more complex to manage and analyze it. AI tools increase the range of data that can be handled and increase the ability to analyze data across and outside of corporate data silos, facilitating analysis when complexity increases for levels that not only appear quantitatively but qualitatively different.

Accountability is necessary not only at the financial audit level but also performance evaluation, respecting the criteria of economy, efficiency, and effectiveness for communicating and reporting in a clear, relevant and timely manner based on sufficient, reliable and relevant information.

The reliability of this non-financial data could be established through integrations and verifications of decentralized applications and storage solutions in Blockchain, using algorithmic techniques to guarantee that the data is unique and not anomalous, generating audit tests that allow to trace and verify. Once the data shipments have been verified, they would be stored in a chain of blocks, generating secure, immutable and auditable "impact tokens" (Suarez et Vargas, 2020).

\section{Impact Analysis}

Once the data has been stored and verified, it enables a continuous analysis on impact, facilitating monitoring and management of the impact to optimizing towards the objectives that have been established based on materiality assessment. 
As was mentioned, even when the standards establish a reference, initially there is no perfect and predetermined single standard and each unit must establish the appropriate framework of indicators applicable according to its environment and its state of the art. For this reason, the frameworks or standard KPIs for monitoring non-financial performance depend entirely on the materiality of the interested parties and must be integrated into the specific control, accounting, and monitoring tools used by each organization.

The difficulty of quantifying the value contribution in terms of social, environmental, and economic impact could be solved, once the materiality criteria have been established and prioritized, the artificial intelligence algorithms are used to find relevant evidence for the specific analysis. Currently, there are different approaches to standards and analysis. As an example, we can cite the literature that uses Natural Language Processing, NLP to identify information relevant to value (Serafeim, 2020).

\section{E. Sustainable Reporting}

Increasing emphasis is being placed on the importance of complete and quality non-financial reporting, reports that should be supported by objective evidence and preferably third-party verified. Sustainability reporting should respond to the need for organizations to demonstrate resilience and respond to the demands of their stakeholders, understanding what they can do as an organization to meet their reporting expectations.

Investors and other stakeholders are expressing their frustration with 'impact washing' practices and the lack of harmonized standards for non-financial reporting. From the analysis of the state of the art in the standardization and regulation for the presentation of sustainability reports, the research highlight the next findings:

The European Union is updating the EU Non-financial Information Directive and is considering developing nonfinancial information standards. The World Economic Forum has published a document on common metrics and consistent reports for the creation of sustainable value, the document defining 21 central metrics. The five main non-financial reporting organizations which are The Global Reporting Initiative (GRI), Sustainability Accounting Standards Board (SASB), International Integrated Reporting Council (IIRC), Climate Disclosure Standards Board (CDSB) and Carbon Disclosure Project (CDP) have published a Statement of Intent, committing to work together to achieve complete corporate reports. The consultation of the IFRS Foundation (International Financial Reporting Standards), still in process, on the establishment of a global framework for non-financial information has already received strong support from other organizations, including IOSCO (International Organization of Securities Commissions).

Sustainability information assurance has become standard practice for large and mid-cap companies around the world, and Spain and Singapore are the two countries that have shown the most growth in the third-party assurance of sustainability reporting since 2017. The Spanish trend may behave like the pusher of the Spanish law on nonfinancial information in 2018, which introduces the requirement of the obligation that non-financial reports of large companies be reviewed by an independent third party (KPMG, 2020). However, the review consists of verifying the disclosure itself but does not offer assurance about the intrinsic quality or reliability of the content or the internal control systems of the organizations, or their ability to supervise an adequate operational monitoring and reporting.

The weakness of the integrated reports proposed to date by most standardization bodies is that they focus integration on financial reporting and sustainability from a financial point of view, considering integrating sustainability into the companies' strategy but not measuring and disclosures all kinds of costs, not only financial ones. However, stakeholders require organizations to be transparent about how they contribute to sustainable development and communicate their impacts on people and the planet comprehensively and consistently.

Sustainable reporting need to include critical areas of evaluation such as:

Report on the risk of loss of biodiversity. A report by the Swiss Re Institute found that more than half (55 per cent) of the world's GDP is dependent on biodiversity and optimally functioning ecosystem services, at a time when one-fifth of the world's countries run the risk of ecosystem collapse (Swiss Re Group, 2020). 
$>$ Report on climate risk and carbon reduction. There is a growing trend to link corporate carbon targets with the global climate target (KPMG, 2020).

$>$ Report on the UN Sustainable Development Goals (SDGs). The Increased pressure on companies from stakeholders, including investors and their peers, to be more transparent on issues such as the impacts of supply chains, Labor standards and diversity may have influenced this jump in reporting. However, SDG reporting is mostly unbalanced and often disconnected from business objectives. Researches suggest that corporate reporting on the SDGs is focused, almost exclusively, on the positive contributions companies make to achieving the goals and avoiding disclosure about their negative impact. A balanced reporting of the SDGs is necessary to demonstrate that an organization is aware of how to contribute to global problems and how it helps to solve them. Disclosure of positive and negative impacts on the SDGs would provide greater transparency by helping build trust between the company and its stakeholders.

As impact assessments, sustainability reports, and reporting guidelines, such as those of the Global Reporting Initiative, have become more rigorous and detailed, organizations have become more aware and accountable for many of their social impacts. However, the evaluations are judging the overall aggregate performance of organizations, weighing all criteria equally, without considering the materiality for a particular organization or industry.

It is necessary to highlight the areas that an organization has the greatest impact on society, so as an example the calculation of a bank's carbon footprint, does not seem to be especially important both either for the bank's economic performance or in terms of reducing the global carbon emissions. In contrast, the issuance of high-risk loans by banks that clients were unable to pay had disastrous social and financial consequences, that not were reported.

Therefore, there is a need to identify specific metrics to focus on specific social problems that have significant effects on specific industries and organizations (Porter et al., 2019).

\section{Conclusions}

2020 was a turning point and the pandemic has accelerated the previous trends to the Covid-19 disruption. We need to innovate to meet the greatest, most urgent, and complex economic, social and environmental challenges in our history

But these innovations must measure, monitor, and report not only in financial terms but also their non-financial performance, especially in terms of sustainability, allowing the understanding of long-term value creation and the assessment of social and environmental risks to incentivize sustainable growth.

Sustainable impact assessment and reporting must take into account dual materiality, focusing on what is important to stakeholders and not just for the organization or its shareholders (simple materiality), for this, organizations must know what is important to its stakeholders through adequate materiality assessment.

Understanding the relevant issues allows the selection of objectives, the definition of the strategy, and the management of its financial, environmental, and social impacts, generating better benefits for all interested parties.

Funding: self-funded.

Author contribution: conceptualization, Suarez B.; data curation, Suarez B. and Vargas A.; formal analysis, Suarez B.; funding acquisition, Vargas A.; investigation, Suarez B. and Vargas A.; methodology, Suarez B.; project administration, Suarez B. and Vargas A.; resources, Suarez B.; software, Vargas A.; supervisión, Suarez B. and Vargas A.; validation, Suarez B; visualization, Suarez B. and Vargas A.; writing-original draft, Suarez B.; writing - review \& editing, Suarez B. and Vargas A.

\section{References}

1. Balluchi F., Furlotti K., Torelli R. (2019). The materiality assessment and stakeholder engagement: A content analysis of sustainability reports. DOI: https://doi.org/10.1002/csr.1813. 
2. Bebbington J., Larrinaga C., et Moneva J. (2008). Corporate social reporting and reputation risk management. Accounting, Auditing \& Accountability Journal, 21, 337-361. DOI: https://doi.org/10.1108/09513570810863932.

3. Brennan et Gray (2005). The impact of materiality: Accounting's best kept secret. Asian Academy of Management Journal of Accounting and Finance, 1, 1-31. Available at: https://www.researchgate.net/publication/228393305_The_Impact_of_Materiality_Accounting's_Best_Kept Secret.

4. Edgley (2014). A genealogy of accounting materiality. Critical Perspectives on Accounting, 25(3), 255-271. DOI: https://doi.org/10.1016/j.cpa.2013.06.001.

5. Font et al. (2016) Font, X., Guix, M., \& Bonilla-Priego, M. J. (2016). Corporate social responsibility in cruising: Using materiality analysis to create shared value. Tourism Management, 53, 175-186. DOI: https://doi.org/10.1016/j.tourman.2015.10.007.

6. Gray, R., Owen, D., et Maunders, K. (1987). Corporate Social Reporting: Accounting and Accountability. London: Prentice-Hall. Available at: http://www.environmentandsociety.org/sites/default/files/key_docs/gray_3_1.pdf.

7. International Integrated Reporting Council (2015). International Integrated Reporting Council (IIRC), \& International Federation of Accountants (IFAC, 2015). Materiality in IR - Guidance for the preparation of integrated reports. Available at: https://www.ifac.org/knowledge-gateway/preparing-future-readyprofessionals/publications/materiality-integrated-reporting.

8. Kogabayev T. et Mazilisuskas A. (2017). The definition and classification of innovation. Available at: https://www.researchgate.net/publication/318180953.

9. Heyns F, (2021). Abbreviated White Paper-Proof of Impact. Available at: https://medium.com/proofofimpact/abbreviated-white-paper-proof-of-impact-89096c307204.

10. Hsu C., Lee W, et Chao W., (2013). Materiality analysis model in sustainability reporting: A case study at Lite-On Technology Corporation. Journal of Cleaner Production, 57, 142-151. DOI: https://doi.org/10.1016/j.jclepro.2013.05.040.

11. Hubbard, G. (2009). Measuring Organizational Performance: Beyond the Triple Bottom Line. Business Strategy and the Environment, 18(3), 177-191. DOI: http://dx.doi.org/10.1002/bse.564.

12. ISO 56002. Innovation management - Innovation management system. Guidance. Available at: https://www.iso.org/standard/68221.html

13. Kishan (2020). ¿Qué tan equivocado estaba Milton Friedman? El equipo de Harvard cuantifica las formas [How wrong was Milton Friedman? The Harvard team quantifies the shapes]. Available at: https://www.bloomberg.com/news/articles/2020-12-01/how-wrong-was-milton-friedman-harvard-teamquantifies-the-ways.

14. KPMG (2020). KPMG Survey of Sustainability Reporting 2020. Available at: https://home.kpmg/uk/en/home/insights/2020/12/kpmg-survey-of-sustainability-reporting-2020.html.

15. Krlev, G., Bund, E. et Mildenberger, G. (2014). Measuring What Matters Indicators of Social Innovativeness on the National Level. Information Systems Management, 31(3), 200-224. http://dx.doi.org/10.1080/10580530.2014.923265.

16. Marr B. (2018). How Much Data Do We Create Every Day? The Mind-Blowing Stats Everyone Should Read. Available at: https://www.forbes.com/sites/bernardmarr/2018/05/21/how-much-data-do-we-create-everyday-the-mind-blowing-stats-everyone-should-read/?sh=1bfa23c260ba.

17. OEDC RT (2018). OECD DAC Roundtable: Accelerating Entrepreneurship and the Development of an Innovation Ecosystem Through Impact Investment and Exploring the Fourth Sector. Available at: https://www.fourthsector.org/oecd-dac-roundtable.

18. Oslo Manual (2018). The Measurement of Scientific, Technological and Innovation Activities. OCDE. Available at: https://www.oecd-ilibrary.org/science-and-technology/the-measurement-of-scientifictechnological-and-innovation-activities_24132764.

19. Phills, J., Deiglmeier, K. et Miller, D. (2008). Rediscovering social innovation. Stanford Social Innovation Review, 6(4), 34-43. Available at: http://ssir.org/articles/entry/rediscovering_social_innovation. 
20. Porter et al. (2019). Where ESG fails. Available at: https://www.institutionalinvestor.com/article/b1hm5ghqtxj9s7/Where-ESG-Fails.

21. Russo M. et Fouts, P. (1997). A resource-based perspective on corporate environmental performance and profitability. The Academy of Management Journal, 40(3), 534-559. Available at: https://www.jstor.org/stable/257052.

22. Savitz, A. et Weber, K. (2006). The Triple Bottom Line: how today's best-run companies are achieving economic, social and environmental success- and how you can too. San Francisco: Jossey-Bass. Available at: https://www.wiley.com/encv/The+Triple+Bottom+Line\%3A+How+Today\%27s+Best+Run+Companies+Are+Achieving+Economic $\% 2 \mathrm{C}+$ Social+and+Environmental+Success+and+How+You+Can+Too\%2C+Revised+and+Updated-p9781118226223.

23. Serafeim G. (2020). Public Sentiment and the Price of Corporate Sustainability. DOI: https://doi.org/10.1080/0015198X.2020.1723390.

24. Slaper, T. et Hall, T. (2011). The Triple Bottom Line: What Is It and How Does It Work? Indiana Business Review, 86(1), 4-8. Available at: http://www.ibrc.indiana.edu/ibr/2011/spring/pdfs/spring2011.pdf.

25. Suarez B. et Vargas A. (2020). Blockchain, Artificial Intelligence, Internet of Things to Improve Governance, Financial Management and Control of Crisis: Case Study COVID-19. DOI: https://doi.org/10.21272/sec.4(2).78-90.2020.

26. Swiss Re Group, (2020). A fifth of countries worldwide at risk from ecosystem collapse as biodiversity declines, reveals pioneering Swiss Re index. Available at: https://www.swissre.com/media/news-releases/nr20200923-biodiversity-andecosystems-services.html.

27. Vavra, J., Munzarova, S., Bednarikova, M., et Ehlova, Z. (2011). Sustainable aspects of innovations. Economics \& Management, 16, 621-627. 7p. 1 Chart. Available at: https://www.acopne.org/sites/acopne.org/files/users/bsien/Assessment\%20of\%20Sustainability\%20Aspects $\% 20 \mathrm{in} \% 20 \mathrm{a} \% 20 \mathrm{Company} . \mathrm{pdf}$.

28. UN, (2015). UN Fundamental Principles of Official Statistics. Implementation Guidelines. Available at: https://unstats.un.org/unsd/dnss/gp/Implementation_Guidelines_FINAL_without_edit.pdf.

29. Wood, D. (1991). Corporate social performance revisited. Academy of Management Review, 16(4), 691-718. DOI: https://doi.org/10.5465/amr.1991.4279616. 